\title{
EL BACHILLERATO Y LAS MUJERES EN COLOMBIA: acción y reacción
}

El bachillerato no es una cosa innatural, exagerada, extraviada, ajena al carácter de la mujer... ¿No ha habido en todos los tiempos mujeres elevadas que se distinguieron en la vida intelectual y contribuyeron con valerosos elementos al bienestar del mundo?... La gran Santa Teresa de Jesús nos dejó una obra profunda de psicología... A Hlildegardis de Bingen y Catalina de Siena no les impidieron ni la santidad ni la dignidad femenina interesarse por los grandes problemas políticos de su tiempo... Que tampoco las ciencias exactas están cerradas al alcance de la mujer prueba los méritos y la fama de una Sonja Kowalewsky y de Madame Curie.

Estas mujeres no perdieron nada de su encanto femenino, al contrario; lo sublimaron y ennoblecieron... El bachillerato no constituye una educación extraordinaria, separada de la vida, sino la base de una vida elevada, una educación sana, completa, armónica, que da la garantía de un desarrollo multilateral, copioso y feliz.

Alice Block, Bogotá, marzo de $1935^{147}$

Durante los debates del Cuarto Congreso Internacional Femenino celebrado en Bogotá en diciembre de 1930. se hizo evidente que si las mujeres iban a ocupar el lugar que les correspondía en la sociedad, era condición Sine qua non que se hicieran cambios radicales en la educación femenina. En consecuencia los parlamentarios liberales y quienes los apoyaban en el Congreso Nacional, al mismo tiempo que promovían los derechos cívicos y legales de la mujer empezaron a encarar la reforma del sistema educativo en todos sus niveles. Hasta 1933, el bachillerato en Colombia estaba restringido a los hombres. Cuando el Gobierno abrió el acceso al diploma de bachillerato a las mujeres, empezaron a efectuarse los cambios necesarios en la educación secundaria femenina.

Durante el Congreso Femenino, Claudina Múnera y María Eastman, junto con otras delegadas, hicieron hincapié en que para llevar a la práctica las iniciativas para la educación secundaria era necesario contar con un decidido apoyo por parte del público. Las reformas requeridas eran además de tal magnitud, que no podían dejarse sólo en manos del sector privado. Tanto Múnera como Eastman insistieron en que las delegadas no deberían contentarse únicamente con la aprobación de resoluciones que pronto pasarían al olvido y procuraron activamente estimular políticas y acciones concretas en el Congreso y en los ministerios del gobierno. Tenían plena conciencia, por otra parte, de que el compromiso con la educación pública formaba parte de la ideología que el partido liberal, que estaba en el poder, había promovido.

Las jóvenes que se contaron entre las primeras en estudiar bachillerato e ingresar a las universidades colombianas experimentaron directamente el impacto de los nuevos principios instaurados por educadores y políticos. Los relatos retrospectivos de sus experiencias personales, en el contexto de los valores propios de la época, dan testimonio

\footnotetext{
Profesora del Departamento de Antropología de la Catholic University, Washington D.C. El presente ensayo hace parte de un libro mayor sobre el ingreso de la mujer colombiana en la educación media Superior que será publicado en 1999.

${ }^{147}$ Alice Block, «El bachillerato de la mujer». El Tiempo, 30 de marzo de 1935. 
de la manera como la mujer colombiana percibió esos momentos históricos excepcionales que la afectaron y que tuvieron también efecto en la sociedad. El bachillerato, tantas veces reclamado. ofrecía muchas posibilidades y ayudaría al logro de los nobles ideales de las mujeres, pero sus aspiraciones se manifestaban con frecuencia en forma practica. Las nuevas oportunidades les permitirían capacitarse para afrontar la lucha por la vida. Confiaban en que la reforma educativa les ayudaría a superarse. Las mujeres estarían mejor preparadas para ganar el sustento y defenderse eficazmente en la vida.

\section{Deseo urgente de una reforma de la educación femenina}

Una serie de reformas efectuadas durante las administraciones de Enrique Olaya Herrera (1930 a 1934) y de Alfonso López Pumarejo (1934 a 1938) se dirigieron a afrontar algunos de los problemas tratados por las delegadas ante el Congreso Femenino. De particular importancia fueron las concernientes a la educación secundaria que hicieron posible la aprobación del bachillerato y el subsecuente ingreso de las mujeres a la universidad.

Durante toda su administración, el Presidente Olaya Herrera lanzó numerosas propuestas de reforma educativa. El cambio en la educación, desde la primaria a la universitaria, era un cometido firme en el programa del partido liberal. Algunos elementos de la reforma pasaron al gobierno de Alfonso López Pumarejo e hicieron parte de su revolución política y social.

El nombramiento, el $1^{0}$ de febrero de 1931, de Rosenda Torres en el Ministerio de Educación Nacional para actualizar la educación primaria y normal fue un paso importante para impulsar la agenda. Ella fue la primera mujer que ocupó tal puesto en el Ministerio y su nombramiento fue bien recibido por parte de un numeroso grupo de funcionarios de la educación, que reconocieron el respeto del que gozaba en la nación.

Doña Rosenda estaba bien preparada para desempeñar el puesto, pues había logrado sobresalir en el campo de la educación, una de las pocas carreras profesionales abiertas a la mujer en aquella época. Había nacido en Antioquia y se había graduado en el famoso Colegio de María en Yaruma], Antioquia ${ }^{148 .}$ Este Colegio fue fundado en 1906 por el notable educador y penalista colombiano Pedro Pablo Betancourt ${ }^{149}$ como modelo para la educación de la mujer. Torres había sido alumna de María Rojas Tejada que, junto con Betancourt, influyó en toda una generación de maestros y administradores sobresalientes de los principales colegios primarios y secundarios de aquella época ${ }^{150}$.

Al iniciar el ejercicio de sus funciones como Director de Educación en Antioquia, en 1912, Betancourt había reorganizado las instituciones de formación de maestros, en especial la Normal de Institutoras de Medellín y la Universidad de Antioquia. Aunque las innovaciones educativas de Betancourt habían despertado oposición entre los

\footnotetext{
${ }^{148}$ Sonny .liménez de Tejada. «Surgimiento y desarrollo de la educación femenina en Antioquia». Revista Universidad de Antioquia, julio-agosto-septiembre de 1964, No 158. pp. 609-624: Hermana Teresa de la Inmaculada, ¿Quién ha educado la mujer colombiana,? (Bogotá, tesis presentada por la Hermana Teresa de la Inmaculada de la Comunidad de la Presentación, para obtener el título de Doctora en Filosofía y Letras. Pontificia Universidad Javeriana, Facultad de Filosofía y Letras, 1960) pág. 264: «Srita. Rosenda Torres prestará sus servicios». El Tiempo. 6 de febrero de 1931.

149 Julio César García, Historia de la Instrucción Pública en Antioquia, $2^{a}$. Ed. (Medellín: Editorial Universidad de Antioquia, 1962): «Llega a Medellín el Dr. Pedro Pablo Betancourt». El Tiempo. 26 de marzo de 1912; «Dr. Pedro Pablo Betancourt» (por G.S.V.). El Tiempo. 22 de octubre de 1933.

150 María Rojas Tejada de Tronchi en Sonny Jiménez de Tejada, op. cit.,pp. 610-611: Julio César García, op. cit.; Agripina Restrepo de Norris, «El triunfo de la mujer colombiana en el Departamento de Caldas». El Tiempo. 21 de enero de 1935.
} 
conservadores y algunos líderes religiosos de entonces, las autoridades regionales y nacionales reconocieron que había creado una atmósfera en la cual había surgido una generación sobresaliente de profesores. Entre ellos, por ejemplo, el núcleo básico de profesores contratado para el Gimnasio Moderno de Bogotá, del cual Rosenda Torres fue parte, nombrada para contribuir al desarrollo de la sección Montessori del Gimnasio. Establecida en 1914, esa institución privada para niños y jóvenes se hizo famosa como centro educativo innovador en Colombia. Torres también fue Subdirectora del Instituto Pedagógico Nacional de Señoritas, la fundación modelo para la capacitación de maestras.

Tenía gran experiencia y amplios conocimientos. Una caricatura titulada «Cómo pasaron las cosas», del maestro Ricardo Rendón. publicada el 9 de julio de 1931 en el diario El Tiempo (ver figura). sugiere que el desempeño de sus funciones correspondió a las expectativas. Se la ve retratada como la autoridad que domina la materia. Los comentarios de Rendón sugerían que el Ministro esperaba que ella trabajara para poder apropiarse de los frutos de su labor ${ }^{151}$.

COMO PASARON LAS COSAS - PCR RENDON

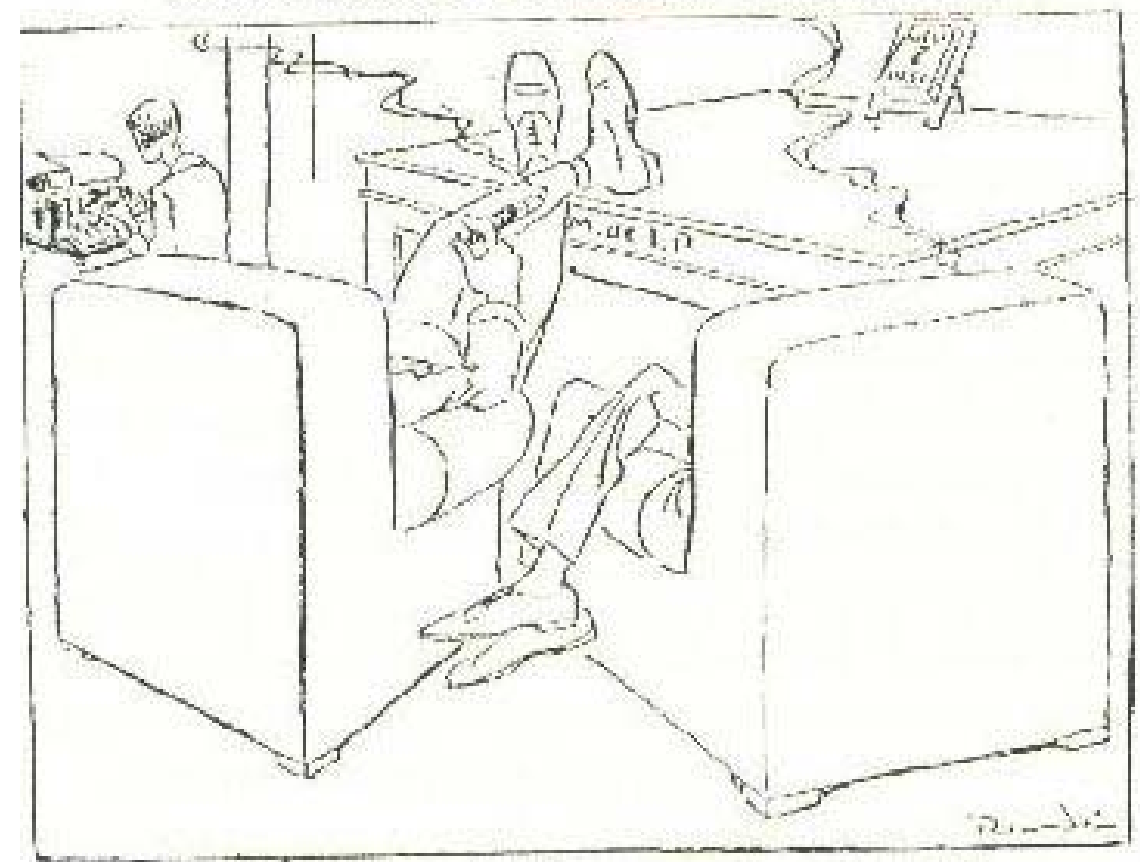

El ministro de instrucción: - Yo creo que debemos hacer algo.

El secretario:-También lo creo yo, señor ministro

El ministro:-Entonces dimite a la señorita torres que como ella es la que sabe, se ponga a trabajar.

Doña Rosenda se mantuvo a la vanguardia de los cambios educativos para la mujer. Cuando el 2 de abril de 1932 se le asignó la División de Práctica de Campo en la recién organizada Facultad de Educación, de la Universidad Nacional de Colombia, fue la única mujer que apareció en los primeros anuncios de la lista del profesorado. A esto siguió en 1935 su nombramiento como Directora de la Escuela Departamental de Artes y Oficios de

\footnotetext{
151 «Rendón» (Ricardo Rendón). «Cómo pasaron las cosas». El Tiempo, 9 de julio de 1931. 
Bogotá, puesto que sólo ocupó por espacio de un año ${ }^{152}$. porque en marzo de 1936. dentro de la reorganización de la educación secundaria. Doña Roseada recibió el nombramiento de profesora de Metodología de la Educación en la Enseñanza Primaria, en el Instituto Pedagógico Nacional de Señoritas, del cual se la nombró Directora al finalizar el año. Esto constituyó un claro honor, puesto que ella era la primera colombiana elegida para dirigir el Instituto después de haber desempeñado tales funciones sus antecesoras, las Doctoras Franziska Radke (de 1927 a 1935)y Carolina Schmitz (1936), miembros de la Misión Pedagógica Alemana en Colombia ${ }^{153}$. La muerte repentina de Doña Rosenda, ocurrida el 4 de enero de 1937, puso fin prematuro a la vida de tan notable educadora colombiana. Ester Aranda fue designada en su lugar ${ }^{154}$.

\section{Las mujeres reclaman un plan nacional para la educación femenina}

En el mes de agosto de 193, no mucho tiempo después de la aparición de la caricatura de Rendón arriba mencionada, el Presidente Olava Herrera nombró Ministro de Educación Nacional a Julio Carrizosa Valenzuela ${ }^{155}$. quien desempeñó un papel importante en la presentación de varias iniciativas sobre educación ante el Congreso Colombiano durante la presidencia de Olava Herrera.

El nuevo Ministro definió con precisión su actitud personal hacia la educación de las mujeres. Carrizosa Valenzuela observó que estaba en desacuerdo con los argumentos que sustentaban los proyectos de ley presentados ante el Congreso. los cuales suponían «que la mujer ocupa un lugar íntimo intelectualmente y que por lo tanto es indispensable elevar su condición hasta el nivel ocupado hoy por el hombre...». Pensaba "que la instrucción secundaria de la mujer adolece de serias deficiencias peto este defecto es general en la enseñanza secundaria aun para el hombre...».

Afirmó en concreto que la educación secundaria no debía tener por Único objetivo preparar a los estudiantes para ingresar a la universidad, sino ofrecer adiestramiento práctico para quienes decidían no seguir una carrera universitaria. Se manifestó a favor de las recomendaciones de la Misión Pedagógica Alemana que estudió la situación de la educación colombiana entre 1924 y 1926. según las cuales en Colombia debería haber tres tipos de educación para las mujeres: 1) «una encaminada a preparar a la mujer para

152 «Nombramiento de Rosenda Torres a la Facultad dc Educación». El Tiempo. 3 de abril de 1932: «Rosenda Torres. Directora. Escuela de Artes y Oficios. El Tiempo. 24 de noviembre de 1935: «Rosenda torres nombramiento Profesora de Metodología. Instituto Pedagógico Nacional». El Tiempo, 10 de marzo de 1936: Jiménez de Tejada, op. cit.. p. 610: ver también. Hermana Teresa de la inmaculada. op. Cit.. p. 264. citando a Julio César Arroyave. Educación y realidad. Bogotá. 1937.

${ }^{153}$ Irene Jara de Solórzano. «Franzisca Radke» El Tiempo. IO de agosto de 1985. La Dra. Radke fué la primera directora del Instituto Pedagógico Nacional Femenino de 1927- 1935. y la primera directora de la Universidad Pedagógica Femenina, de 1955- 1957. Recibió su título de la Escuela Normal de Aquisgrán. Se especializó en las Universidades de Bonn y de Berlín y la Universidad de Marburg le otorgó su doctorado. En 1977. con motivo de las bodas de oro del Instituto Pedagógico Nacional, el Gobierno de Colombia le otorgó la "Gran Medalla Nacional. General Francisco de Paula Santander.» (Grado de Comendador), en reconocimiento de sus contribuciones a la organización y dirección del instituto. Ver «Decreto Número 550 de 1977 (marzo 14) por el cual se concede una condecoración al mérito educativo». Documentación Educativa. Universidad Pedagógica Nacional. Volumen 3. Nos. 13 y 14. 1977.

154 «Doña Rosenda Torres - muerte inesperada». El Tiempo. 6 de enero de 1937: «La Nueva Directora del Instituto Pedagógico Nacional llegará esta semana». El Tiempo. 13 de enero de 1937: "La reorganización del Instituto Pedagógico Nacional se iniciará muy pronto». El Tiempo. 22 de enero de 1937:. Ester Aranda nació en San Gil, Santander y se graduó en la Escuela Normal de San Gil, Santander del Sur, con diploma de Institutora. Se especializó en Educación en el Instituto Pedagógico Nacional. Bogotá. Livia Stella Melo. Valores Femeninos de Colombia (Bogotá: Carvajal y hermano. 1967). P. 121.

${ }_{155}$ Julio Carrizosa Valenzuela, ingeniero, participó activamente en la reforma de la Facultad Nacional de ingeniería de Bogotá. 
cumplir debidamente con su misión en el hogar y en la sociedad.»2) «Otra que abarca la preparación completa de la enseñanza secundaria» y finalmente 3)..... que le dé una enseñanza comercial suficiente para permitirle ganarse la vida con menos dificultad» ${ }^{156}$.

Esperaba además que como resultado de las reformas propuestas la universidad ofreciera, aparte de las opciones tradicionales en leyes, medicina, ingeniería y áreas técnicas conexas, una mayor variedad de selección en cuanto a carreras profesionales lo cual ampliaría las posibilidades para que la mujer se preparara para el mercado de trabajo, ya «... que en los países cuyas universidades son frecuentadas por mujeres, éstas encuentran en la universidad profesiones más variadas, algunas de las cuales son derivaciones de las nombradas, pero que les ofrecen mayores oportunidades para ganarse la vida».

El Presidente Olaya Herrera expidió el Decreto $N^{0} 1487$ de 1932 (13 de septiembre ). sobre reforma de la enseñanza primaria y secundaria. El decreto dispuso que la educación primaria tendría en todo el país una duración de cuatro años, con programas de estudio preparados por el Ministerio ${ }^{157}$. En Bogotá y en las capitales de los Departamentos se establecerían escuelas modelo y se esperaba que, a medida que la situación fiscal lo permitiera, tales modelos se difundieran por todo el sistema de educación primaria. Habría también un curso de «dos años de escuela complementaria, orientada hacia los distintos oficios o artes para los alumnos que no aspiren a seguir estudios secundarios..,».

La segunda enseñanza se convertiría en un programa de seis años exigido a quienes solicitaran su admisión a la universidad, a los que aspiraran a ser maestros y en general a quienes quisieran obtener el diploma de bachillerato. El decreto dispuso también que los estudiantes que completaran el ciclo secundario y desearan obtener el diploma de bachillerato (exigido por el Gobierno para entrar en la universidad) tendrían que presentar un examen de cultura general en Bogotá o en las capitales de departamento (ver Ley 56 de 1927). Finalmente, los estudiantes que después de terminar el bachillerato quisieran seguir la carrera del magisterio podrían solicitar admisión a la Facultad de Educación ${ }^{158 .}$

El 2 de febrero de 1933 el decreto se extendió también a la enseñanza secundaria para señoritas. Por Decreto Presidencial Número 227 de 1933 (2 de febrero) todas «Las

\footnotetext{
156 «Sobre instrucción pública hubo un gran debate ayer». El Tiempo, 11de agosto de 1931: «El programa del nuevo Ministro de Educación». El Tiempo 12 de agosto de 1931. La Misión Pedagógica alemana (1924-1926) vino a Colombia por invitación del Gobierno nacional para realizar un estudio de la educación Colombiana. En agosto de 1925 le presentaron al Ministro de Educación un proyecto de ley orgánica de la educación. Bohórquez comenta que aunque el Congreso Nacional no aceptó el proyecto legislativo, la ley 56 de 1927 (10 de noviembre). «por la cual se dictan algunas disposiciones sobre instrucción pública. » que hizo obligatoria la enseñanza primaria, fue consecuencia del plan de esta Misión, Luis Antonio Bohórquez Casallas. La Evolución Educativa en Colombia (Bogotá: Publicaciones Cultural Colombiana, 1956), pp. 436438. La Misión también recomendó preparación de Bachillerato para la mujer, como una de las opciones de educación secundaria femenina, así como también cursos cortos de carreras practicas (Helg. Pp. 117-118): Antonio José Uribe. Política Instruccionista (Bogotá: Imprenta Nacional. 1926).

${ }^{157}$ Colombia. Decreto $N^{0} 1487$ de 1932 (13 de septiembre), sobre reforma de la enseñanza primaria y secundaria. Presidente de la República, Enrique Olaya Herrera, Ministro de Educación Nacional, Julio Carrizosa Valenzuela.

${ }^{158} \mathrm{lbid}$. Anteriormente, las escuelas normales preparaban a los estudiantes para enseñanza a nivel de primaria. Los programas nuevos darían preparación para enseñanza secundaria. Ver Aline Helg. "La educación primaria y secimdaroa durante el primer gobierno de Alfonso López Pumarejo (1934-1938). (Proyectos y realizaciones), Revista Colombiana de Educación, Bogotá, N ${ }^{0} 6$. II Semestre de 1980, pp. 9-36; Alfredo Molano y César Vera, Evolución de la Política educativa durante el Siglo XX. Primera parte 19001957 (Bogotá, Centro de Investigaciones, Universidad Pedagógica Nacional, 1982).
} 
disposiciones del Decreto Número 1487 de 1932 (13 de septiembre) sobre reforma de la enseñanza primaria y secundaria, se hacen extensivas a la enseñanza femenina». Se indicaba que «Los colegios oficiales y privados de señoritas que aspiren a dar el título de bachiller 0 el de institutora, refrendado por el Gobierno, deberán Ilenar los requisitos establecidos en el citado Decreto y organizarán sus planes de estudio de conformidad con lo dispuesto por el Ministerio de Educación Nacional para los colegios de hombres» ${ }^{159}$.

El Decreto Presidencial $\mathrm{N}^{0} 227$ del 2 de febrero de 1933. mediante el cual se confería a los colegios colombianos la facultad de preparar a la mujer para el bachillerato, despertó el entusiasmo de todo el país. En la práctica, sin embargo, la aplicación del cambio no fue fácil. Claudina Múnera y un grupo de mujeres de Manizales exhortaron al Congreso para que tomara medidas más enérgicas para que el Decreto pudiera aplicarse.

En un memorial al Presidente del Senado colombiano de fecha del 22 agosto de 1933 reclamaron que había urgente necesidad de adoptar un plan nacional que contuviera guías específicas para la educación femenina. La educación de las mujeres tenía máxima importancia en Colombia. Dijeron que la nación debería preparar a todo el pueblo para vivir en comunidad, practicar la solidaridad social y trabajar a fin de hacer frente a la lucha por la vida. Pedían que se hiciera un estudio completo y sistemático de los planes de estudio y de programas adaptados a las necesidades de la mujer colombiana ${ }^{160}$.

De las ocho secciones del escrito, varias fueron especialmente significativas. En una de ellas se aducía: «...no es suficiente para resolver el problema de la educación femenina en Colombia, el que se hayan abierto a la mujer las puertas de la Universidad y las de los institutos en donde se da bachillerato en el país en la forma autorizada por las últimas leyes y decretos nacionales.» Se afirmaba que "es de público conocimiento que en el país no ha existido una educación oficial ni particular que prepare a la mujer colombiana para defenderse eficazmente en la vida.., ni para contribuir.., al progreso general de la República». Temían, además, que «Los antecedentes de la vida civil en nuestra patria, su sistema actual de costumbres. el carácter especial de nuestra raza... nos tienen convencidas de que la educación mixta no sería aceptada ni produciría los buenos resultados que se necesitan.... ${ }^{161}$.

En otra sección se afirmaba que la experiencia había demostrado que la vida en el hogar exige de las mujeres no sólo formación moral. "sino también un conjunto sólido de conocimientos científicos y técnicos para atender debidamente a sus diversas funciones...» Se insistía que a pesar de las diferencias biológicas entre el hombre y la mujer, es preciso «.. .que la mujer, siempre que le sea necesario para su vida y para su bienestar económico, realice su trabajo en múltiples oficios y profesiones que armonizan con su idiosincrasia y con la misión que le ha confiado la naturaleza».

Es cierto que los legisladores colombianos habían empezado a aprobar leyes que favorecían a la mujer, tales como la Ley 28 de 1932, que hizo extensivos los derechos civiles a la mujer casada. La nueva legislación «... hace indispensable en ella una preparación completa en todos los aspectos de la vida.., para que los efectos de la ley no

\footnotetext{
${ }^{159}$ Colombia. Decreto $N^{0} 227$ de 1933 (2 de febrero). «Por el cual se dictan disposiciones sobre enseñanza secundaria para señoritas». El Presidente de la República, enrique Olaya Herrera. El Ministro de Educación Nacional, Julio Carrizosa V.

${ }_{160}$ Memorial al Señor Presidente del Honorable Senado de la República, de Claudina Núnera y suscritas mujeres colombianas, vecinas de Manizales. El Tiempo. 22 de agosto de 1933.

161 Ibid 
vengan a ser nugatorios en la realidad quedando sin efecto alguno la intención patriótica del legislador...».

Finalmente, las mujeres pidieron que se adquiriera un compromiso para que la educación a nivel de bachillerato fuera la base de la educación femenina, «...complementado por cursos especiales que requiere la índole particular de la mujer colombiana...». Aseguraron que los recientes decretos relacionados con la educación de bachillerato (el 1487 del 13 de septiembre de 1932 y el 227 de 1933) únicamente autorizaban que las mujeres lo estudiaran, pero no había un plan de acción. Los colombianos no podían vivir de la ilusión de que las instituciones privadas tuvieran la responsabilidad principal de organizar, con la urgencia requerida, los colegios que necesitaban las mujeres.

Las autoras del memorial concluían que, en vista de la magnitud de las deficiencias en la educación de la mujer, como primer paso el Congreso debería corregir la situación «...empezando por la creación y organización de colegios especiales para el bachillerato femenino en todas las capitales de departamento de la república...» Esperaban que el Senado colombiano les prestara oídos como a «la voz patriótica de la mujer colombiana,» según había ocurrido en anteriores ocasiones ${ }^{162}$.

El llamado a que se creara un plan nacional para promover iniciativas de educación femenina en el país se estaba perfilando como el tema principal en los cambios educativos propuestos en aquella época y en las deliberaciones acerca de los modelos apropiados para la educación de la mujer, Había en realidad pocos colegios de estudios secundarios para mujeres en el país.

Conviene señalar que el terna de la educación pública y privada había sido discutido a lo largo de la historia de Colombia. Aline Helg anotó que durante el período que terminaba en 1930 , el $29 \%$ de los estudiantes a nivel secundario estaba en colegios oficiales. La terminología "colegio oficial» era, sin embargo, engañosa. Helg señala que a un colegio se le denominaba oficial si sus instalaciones pertenecían al gobierno nacional 0 departamental. El Estado delegaba con frecuencia la administración de sus colegios a personas privadas o a órdenes religiosas. Además, los colegios oficiales no eran gratuitos: los padres tenían que pagar la matrícula de admisión y las mensualidades, los uniformes y los útiles escolares. Las becas del gobierno para estudiantes meritorios pertenecientes a familias de escasos recursos, dependían a veces de influencias políticas.

La educación secundaria dependía en gran parte de la iniciativa privada. por lo cual el Gobierno había establecido una política general a la que todos los colegios debían conformarse para obtener la aprobación oficial de los diplomas otorgados. Había, sin embargo, diferencias básicas entre los colegios masculinos y femeninos de secundaria. Los colegios masculinos ofrecían a sus alumnos los diplomas de bachillerato que se exigían para ingresar a la universidad. Los femeninos daban diplomas o certificados de haber cursado sus programas de estudio. Preparaban a las alumnas para el magisterio o para el desempeño de diversas ocupaciones ${ }^{163}$.

\footnotetext{
162 Ibid.

${ }^{163}$ Aline Helg. Op. cit., pp. 74-75. Helg comenta que en esta época bahía cuatro categorías de colegios particulares a nivel secundario en Colombia: a) los colegios dirigidos por miembros de congregaciones religiosas (aproximadamente el 50\%): b) los colegios de secundaria dirigidos por personas laicas colombianas (aproximadamente el $40 \%$ ): c) colegios con orientación liberal; y d) colegios extranjeros dirigidos por laicos, tales como los establecidos por alemanes. ingleses o norteamericanos.
} 


\section{Enfrentando el reto en Bogotá}

En torno de la reforma del bachillerato hubo puntos de vista encontrados acerca de los modelos que se deseaba poner en práctica para la educación de las mujeres. Los directores de los colegios que acogieron los nuevos planes se encontraban a la vanguardia de esas deliberaciones. Actuaban por un compromiso ideológico. Necesitaban también estrategias personales y colectivas para lograr buenos resultados en la implantación de las metas que se quería alcanzar.

Las primeras jóvenes que obtuvieron el grado de bachillerato e ingresaron a la universidad aprendieron por propia experiencia que el cambio educativo no era tan sólo cuestión de crear nuevos programas de estudio y expandir el personal docente. Los relatos retrospectivos de un grupo selecto de mujeres que formaron parte de los primeros núcleos de bachilleres y graduadas universitarias colombianas reflejan esos sentimientos en sus respectivas regiones. Tanto las mujeres como sus familias estaban decididas a seguir un nuevo rumbo de acción, superar las dificultades y encabezar una indispensable revolución.

Los colegios públicos y privados se prepararon para cumplir con los requisitos que los convirtieran en instituciones capacitadas para otorgar el diploma de bachillerato. En Bogotá, el Colegio Departamental de La Merced fue uno de los primeros colegios oficiales que otorgó diplomas de bachillerato. Pocos años después, en Medellín, el Instituto Central Femenino fue, a semejanza del Colegio de La Merced, una institución pionera. Esos colegios se convirtieron en centros de enseñanza avanzada en donde se preparaba a un número considerable de mujeres jóvenes para su ingreso a la universidad a fin de estudiar profesiones liberales. Un núcleo de colegios privados regidos por miembros de órdenes religiosas femeninas, así como otras instituciones privadas laicas, también empezaron a reorganizarse.

El histórico Colegio Departamental de La Merced, fundado en Bogotá en 1832, fue la primera institución oficial colombiana que ofreció educación para la mujer, y en 1935 fue el primero en el país en recibir autorización del Ministerio de Educación para ofrecer el bachillerato a las mujeres ${ }^{164}$.

La Directora el Colegio de La Merced era entonces Doña Inés Álvarez Lleras de Bayona Posada, nombrada en 1933, y quien había participado activamente en los planes para la reorganización propuesta. Doña Inés había cursado sus estudios en el Colegio de María Auxiliadora de Bogotá, fundado por la congregación, religiosa de la Hijas de María Auxiliadora, conocidas popularmente como «Salesianas.» Dicho Colegio había sido uno de los que prepararon a muchas jóvenes para la carrera del magisterio y para diversas actividades prácticas. Doña Inés, que descendía de una distinguida familia de intelectuales, era conocida escritora. Entre las obras que publicó se encuentra El feminismo en Colombia (1932). Sus antiguas alumnas la elogiaban y la describían como una Directora que tenía refinadas virtudes y profunda devoción a los valores del ideal femenino y a la tradición católica que por entonces prevalecía ${ }^{165}$.

\footnotetext{
164 Julia Isabel Acuña de Moreno, Albores de la educación femenina en la Nueva Granada. Historia del Colegio Departamental de La Merced (Bogotá, Editorial Mineducación, 1989): José Antonio León Rey. «El Colegio de La Merced», Bo/etin de la Academia Colombiana, N ${ }^{0} 123$, enero. febrero y marzo de 1979; Guillermo Hernández de Alba. Aspectos de la cultura en Colombia (Bogotá. Biblioteca Popular de Cultura Colombiana, 1947), pp. 239-250. Luis Antonio Bohorquez Casallas, op. cit., pp. 282-289.

165 Inés Álvarez Lleras de Bayona nació en Bogotá. Inició sus estudios en el Colegio de la Presentación y posteriormente estudió pedagogía en el Colegio de María Auxiliadora que le otorgó sus diplomas de Digitalizado por RED ACADEMICA
} 
En 1935, cuando el Colegio de La Merced abrió sus puertas con una nueva sección de bachillerato, Alice Block, connotada pedagoga alemana, fue nombrada Directora de esa unidad. Tal nombramiento se hizo bajo la autoridad de Don Luis Tamayo, Gobernador de Cundinamarca. Block, graduada en la Universidad de Bonn, había enseñado en Bonn y en Colonia. Se la invitó a Colombia en 1931, a raíz de la muerte de María Hassebrick, una de las integrantes de la Misión Pedagógica Alemana que había llegado a Colombia en $1926^{166}$. Block no permaneció mucho tiempo con el Instituto Pedagógico y en 1933 fundó su propio colegio secundario femenino, el Instituto Alice Block, que fue considerado un modelo avanzado para la época. Las alumnas cursaban ciencias, idiomas (como inglés, francés y alemán) y varias otras materias no incluidas por lo común en los programas de estudio de los colegios secundarios femeninos típicos de aquellos años.

En una entrevista publicada en El Tiempo el 30 de marzo de 1935, Block explicó sus puntos de vista acerca del bachillerato para la mujer y de las mujeres con mayor grado de educación. Se refirió a las animadas discusiones que habían tenido lugar en Colombia como resultado de la iniciativa gubernamental de establecer estudios de bachillerato en el Colegio de La Merced. La palabra «bachillera», indicó, había adquirido connotaciones contradictorias, había quienes asociaban dicha palabra con una mujer de sólidas características intelectuales, morales y sociales, mientras que otros la utilizaban para referirse a personas de dudosa identidad sexual.

Aseveró con firmeza que el bachillerato no era ajeno al carácter femenino. En todas las épocas de la historia hubo mujeres que destacaron, como Teresa de Jesús, quien dejó profundos escritos y Roswitha de Gondershem, famosa por sus versos latinos. Figuras notables, como Hildegardis de Bingen y Catalina de Siena, combinaron santidad y dignidad con la participación en los grandes temas políticos de su época. Otras, como Sofia Kovalevskaia y Madame Curie, demostraron que las ciencias exactas no les eran inasequibles. Ninguna de esas mujeres perdió su identidad femenina. Ciertamente, dijo. las respetables matronas de la histórica Santa Fe de Bogotá no tendrían por qué sentirse avergonzadas por las aspiraciones de la nueva generación femenina ${ }^{167}$.

Para concluir invitó a las aspirantes a admisión para que visitaran el Colegio y trataran de planear su posible traslado desde otros colegios que carecían de sección de bachillerato. Las alumnas que llegaban de otros colegios y las ya matriculadas en La Merced, necesitaban casi siempre seguir cursos de ciencias (química, física y biología, por ejemplo), matemáticas, idiomas y materias conexas.

Maestra e Institutora de Grado Superior. Su padre, Enrique Alvarez Bonilla, fue un educador y escritor conocido y su madre, Elena Lleras Triana, fue la hija de Lorenzo María Lleras, conocido por su amor a la literatura y al teatro, así como también a la educación. Doña Inés habia sido miembro de la congregación religiosa "Hijas de María Auxiliadora,» donde se conoció con el nombre de Hermana helena Álvarez Lleras. En 1915 contrajo matrimonio con el poeta Daniel Bayona Posada. Enviudó en 1920. Julia Isabel Acuña. op. cit., pp. 126-127: Hermana Teresa de la Inmaculada, p. 162; Livia Stella Melo L., op. cit., pp. 123-124; Publicaciones selectas: El Feminismo en Colombia (Bogotá: Escuela Tipográfica Salesiana, 1932). y Matrimonio y Divorcio (Bogotá: Escuela Tipográfica Salesiana, 1936).

166 Las Doctoras Cecilia Cardinal de Martín, Blanca Garavito de Avila, exalumnas del Instituto Alice Block, y otras personas me proporcionaron datos sobre la Dra. Alice Block. Ver también. «La Dra. Alice Block... en el Colegio Departamental de La Merced». El Tiempo, 18 de enero de 1935: "Un colegio modelo para niñas». El Tiempo. 17 de julio de 1933; «Bachillerato Femenino». El Tiempo. 18 de enero de 1935.

los miembros de la Misión Pedagógica alemana que se dedicaron al recién establecido Instituto Pedagógico Nacional fueron: Franziska Radke, Richard Ostermayer, Hans Huber, Carolina Schmitz, María Hasebrick y Gertrud Fussiers. El Tiempo, 15 de agosto de 1926; "La nueva misión de pedagogos alemanes», Helg, op. cit., p.. 126.

${ }^{167}$ Alice Block., «El bachillerato de la mujer», op. Cit. 
Nuevos y destacados profesores fueron nombrados en el Colegio de La Merced. La activa colaboración de ese grupo de profesionales hizo posible materializar las primeras etapas del programa de bachillerato, de acuerdo con el programa de estudios exigido por el Ministerio de Educación Nacional. La lista de profesores era en realidad una lista de personalidades de relieve nacional. Figuraban, entre otros, el ex Presidente Enrique Olaya Herrera en educación cívica, el Obispo Juan Manuel González Arbeláez en educación moral y religiosa, Rafael Maya en literatura e historia del arte, Antonio Gómez Restrepo en composición e interpretación literaria, Yamil Aljure en francés, Alice Block en biología y alemán, Enrique Otero D'Costa y Trinidad Fierro en historia Patria e historia universal, Fenita Hollman en economía doméstica y Alfonso del Corral, el médico escolar, en fisiología e higiene ${ }^{168}$.

A pesar de la inspiración y competencia que aportó al Colegio de La Merced. Block duró poco en ejercicio de sus funciones. A mediados de abril de 1935, precisamente pocos meses después de recibir su nombramiento, renunció y regresó a su Instituto. La brevedad de su paso se debió, sin duda, a los cambios registrados por entonces en la administración del Colegio de La Merced. A finales de febrero de 1935, justo un mes antes de la apertura del recién reorganizado Colegio, las estudiantes iniciaron protestas públicas debido a los rumores de que Doña Inés, su Directora, iba a ser reemplazada. Se dijo que había desacuerdos entre Doña Inés y Alfonso del Corral, Director de Instrucción Pública del Departamento de Cundinamarca.

Un grupo de estudiantes acudió al Palacio Presidencial para solicitar que no fuera cambiada la Directora. Se dice que el Presidente Alfonso López les ofreció tener muy en cuenta sus observaciones, asegurándoles que sería fiel a su compromiso de apoyar el bachillerato femenino en Colombia ${ }^{169}$. En su correspondencia con Don Luis Tamayo. Gobernador del Departamento. Doña Inés se refirió a los hechos que la condujeron a renunciar a su cargo.

Doña Inés reiteró que a consecuencia de un incidente de poca monta, pero principalmente por "fatiga.» presentó su renuncia a fines de enero de 1935. No obstante, el Gobernador la animó a permanecer en su cargo. Según escribió Doña Inés más tarde se la acusó de obstaculizar la reorganización del bachillerato en La Merced. Su autonomía como Directora se vio restringida por hechos tales como el nombramiento de un nuevo cuerpo docente sin que se la hubiera consultado ${ }^{170}$. Tras nuevos malentendidos con las autoridades gubernamentales, presentó su renuncia definitiva. Dentro del mes siguiente fundo, bajo su dirección, otro colegio, el Ateneo Femenino. Algunas de sus exdiscipulas y varios profesores del Colegio de La Merced se unieron a ella en esta nueva institución ${ }^{171}$.

Mientras tanto, el $1^{0}$ de marzo de 1935 el Subdirector de Educación del Departamento. Gabriel Anzola Gómez, anunció que Paulina Gómez Vega había sido seleccionada como

\footnotetext{
168 «El bachillerato femenino. Nombrado el personal de profesores de la Merced», El Espectador 23 de enero de 1935; «Ayer fue nombrado el profesorado para el Colegio de la Merced». El Tiempo 24 de enero de 1935.

169 «Hay grande agitación en el Colegio de la Merced actualmente», El Tiempo, 28 de febrero de 1935.

${ }^{170}$ Carta a Don Luis Tamayo, Gobernador dcl Departamento de Cundinamarca, de Inés Alvarez de Bayona, Bogotá, 2 de Febrero de 1935, en «La Directora del Colegio se niega a presentar renuncia». El Tiempo, $1^{0}$ de marzo de 1935.

${ }^{171}$ Carta a Don Luis Tamavo. Gobernador de Cundinamarca, de Inés Alvarez de Bayona. $1^{0}$ de marzo de 1935, en El Tiempo, 3 de marzo de 1935. «Ateneo Femenino». El Tiempo, 3 de marzo de 1935: "Ocho celadoras renunciaron ayer tarde de manera formal». La nueva Directora se encargará el lunes próximo. La Sra. Alvarez Lleras funda un nuevo colegio. El Tiempo 2 de marzo de 1935 
nueva Directora del Colegio. Los antecedentes de Doña Paulina en cuanto a educación y ciencias parecían apropiados en ese período de transición e innovación en el Colegio.

En efecto, ya antes de sus viajes de estudio a los Estados Unidos, Doña Paulina había ejercido el magisterio en varias de las principales Escuelas Normales para señoritas de Colombia. Graduada de la Escuela Normal de Institutoras de Tunja, fue Subdirectora de la Escuela Normal de Señoritas de Santa Marta y desempeñó otros puestos. En 1919, cuando viajó por primera vez a los Estados Unidos era Directora de Prácticas e Instructora de Métodos de Enseñanza en su alma mater, la Escuela Normal de Tunja ${ }^{172}$. A fines de la década de los años 20 , tras su retorno a Colombia trabajó en aspectos de investigación e instrucción de salud pública nacional.

Su interés en los asuntos de la mujer se hizo cada vez más evidente a través de las actividades que desarrollaba, como por ejemplo su labor con la Dirección Nacional de Higiene en la Escuela Nacional de Enfermeras Visitadoras, la recién inaugurada escuela de enfermería de Bogotá ${ }^{173}$. En 1932, cuando la Federación de Empleadas se convirtió en una entidad independiente separada de su organización matriz (la Liga de Damas Católicas), Doña Paulina fue electa vicepresidenta. Desde esa posición colaboró en compañía de sus colegas en los esfuerzos que entonces se hicieron para organizar a las trabajadoras de la clase media de Bogotá en conjunto con movimientos similares en otras regiones del país. En septiembre de ese mismo año sus actividades se interrumpieron temporalmente cuando recibió la buena noticia de que la American Association of University Women le había otorgado la beca latinoamericana para estudios de posgrado en la Universidad Johns Hopkins ${ }^{174}$. Recibió el grado de Maestría en Ciencias de dicha Universidad el 12 de junio de $1934^{175^{\circ}}$.

Algunas de las opiniones de Doña Paulina respecto de su experiencia durante el primer año como Directora del Colegio de La Merced aparecieron en un artículo sobre la educación femenina publicado en la revista Educación ${ }^{176}$. Al subrayar los factores que

\footnotetext{
${ }^{172}$ El Tiempo, $1^{0}$ de marzo de 1935.

${ }^{173}$ «Subdirectora de la Escuela Normal de Santa Marta... la Srita. Paulina Gómez Vega». El Tiempo. 22 de febrero de 1913; Paulina Gómez Vega. «From Bacteriology to Beauty Culture", Journal of the American Association of University Women, Washington DC., octubre de 1934. Vol. XXVIII. No 1. pp. 27-32: «Pagove» (Paulina Gómez Vega) «La Escuela de Enfermeras Visitadoras». El Tiempo, 29 de marzo de 1931.

174 «Triunfo de nuestra Vice Presidenta». Heraldo Femenino, agosto de 1932; «Srita. Gómez Vega sale para los Estados Unidos», El Tiempo, 11 de septiembre de 1932.

175 Doña Paulina quería estudiar para su Doctorado en Ciencias (Ph.D.). Por razones desconocidas no siguió para el doctorado después de recibir su Maestría en Ciencias (M.Sc.) en la universidad de Johns Hopkins. Le solicitó fondos a la Fundación Rockefeller para estudiar procedimientos en varios laboratorios de salud pública en los Estados Unidos pero le negaron dicha solicitud. En los Archivos de la Fundación Rockefeller se comenta: «Paulina Gómez Vega es una líder del movimiento feminista en colombia... activa en asociaciones de mujeres y de mujeres trabajadoras». Se caracteriza como persona con "más interés en llegar a ser líder feminista que en trabajo de las ciencias de la salud». Es posible que estas observaciones contribuyeran a que no se aprobara su solicitud. Sin embargo, en el Departamento de Bacteriología de Johns Hopkins se dedicó plenamente a su carrera científica, y para su tesis de grado trabajó con la científica Dra. Janet Howell Clark, sobre el tema «Studies on Certain Monilias and Related Fungi». Regresó a Colombia en septiembre de 1934. Nota a la autora de Evelyn James, Office of the Registrar, Johns Hopkins Universitv, Maryland, 11 de enero de 1990. Paulina Gómez Vega en Idealism at Work, Eighty Years of American Association of University Women Fellowships, Washington, D.C., A.A.U.W., 1967, p. 53, en Archives of the American Association of University Women, Washington D.C.; Fellowship Records, Gómez Vega, Miss Paulina, carta de George Bevier a HHH, 30 de enero de 1934; Nota de George Bevier y HHH, 6 de mayo de 1934, Rockefeller Archive Center en International Health Board Fellowship Records, RG2, Colombia.

${ }_{176}$ Paulina Gómez Vega, «La educación femenina en Colombia», Educación, Vol. 3. N²8-29, nov.- dic.,
} 1935, pp.. 653-660. 
determinaron las actitudes de las mujeres colombianas hacia las actividades intelectuales y el trabajo serio, describió los tipos de mujer ideal que prevalecían y señaló la necesidad de forjar modelos alternativos:

Es bien sabido que por mucho tiempo en nuestra literatura y en la literatura española el tipo más admirado de mujer es el de la niña dulce, inocente y tímida, flor oculta a quien un Don Juan descubre por la fragancia de sus virtudes. Todas hemos derramado nuestras lágrimas sobre las páginas de 'María'177 y casi todas hemos soñado con un amor y una muerte semejante a los suyos. No hemos tenido muchos libros que elogien a la mujer de carácter y personalidad definidos, que tiene ambición de surgir por méritos propios y verdaderos y que lucha por sus derechos y los derechos de otros después de haber aprendido que tiene deberes y sabe cumplirlos. Ese tipo de mujer más humano es el que aspiramos a que se forme en éste y en los otros colegios de educación femenina ${ }^{178}$.

Las reminiscencias colectivas de varias estudiantes de La Merced, que posteriormente ingresaron a la universidad, Matilde León Espinel de Fómeque, Cundinamarca, Gabriela Castro de Barrera de Bogotá, Lucila Galindo de Casij de Ortega, Tolima. Soledad Peña de Guerra de Girardot, Cundinamarca, y Esther Saavedra de la Espriella, de Bogotá, subrayan distintos aspectos de los dos años de labor de Doña Paulina como Directora del Colegio de La Merced ${ }^{179}$.

Las antiguas estudiantes estaban orgullosas del Colegio Departamental de La Merced, que había sido fundado para «hijas de próceres». Entre ellas mismas las estudiantes clasificaban a sus compañeras en dos grupos: las que disfrutaban de una beca y las que pagaban por sus estudios. Recordaban cómo Doña Paulina había apoyado con firmeza el nuevo programa de estudios del bachillerato, el cual les había permitido estar en contacto con figuras muy conocidas de Colombia. Promovía los deportes y las artes, tanto que el equipo de baloncesto de La Merced se convirtió en campeón nacional en la categoría de colegios para mujeres. Por otra parte, su fuerte orientación hacia la salud pública la había llevado a abolir ciertas costumbres establecidas en la vida de los internados. Esos cambios fueron importantes puesto que en aquella época se exigía que todas las estudiantes fueran internas. El mejor recuerdo que guardaban de aquello era la desaparición de la piscina que todas debían compartir y en la que todas las jóvenes para bañarse debían vestir el "chingue». aquella ropa tan especial (un vestido de baño largo de lana negra). siempre bajo la supervisión del personal del colegio.

Algunos padres criticaban a Doña Paulina por ser tan directa tanto con ellos como con sus hijas. No dudaba en decir a las estudiantes que si no se dedicaban más al estudio más tarde sólo servirían para casarse y dar a luz «cinco hijos», Felicitaba a las estudiantes que destacaban en clase y les ayudaba a considerar programas de carreras universitarias en Colombia y en el extranjero. Las doctoras Matilde León y Soledad Peña de Guerra insistían en que ella había servido como catalizador central para los cambios necesarios en la época y comentaban: «Nos sacó adelante y llevó a cabo la transformación necesaria».

\footnotetext{
${ }^{177}$ Se refiere aquí a la conocida novela María de Jorge Isaacs y el idilio romántico de la joven María y Efraín en una hacienda de caña de azúcar del Valle del Cauca.

178 Gómez Vega, Educación, op. cit.

179 Entrevistas: Dras. Matilde León Espinel, Gabriela Castro de Barrera, Soledad Peña de Guerra. Lucila Galindo de Casij. y Esther Saavedra de la Espriella, Bogotá. 
Durante esos años de transición en La Merced, la sección de bachillerato atrajo estudiantes de otras instituciones que aún no estaban preparadas para ofrecerlo, en especial alumnas del colegio nacional modelo para la formación de profesoras, el Instituto Pedagógico Nacional de Señoritas. La Dra. Blanca Garavito de Avila formó parte del primer grupo de estudiantes del Instituto que se transfirió a La Merced. Describió ese cambio de la siguiente manera:

Yo no quería ser profesora, ni quería ejercer en la Anexa... Junto con otras compañeras nos trasladamos al Colegio de La Merced. La Dra. Block tenía un contrato con el Ministerio de Educación para organizar el programa y las clases de bachillerato en La Merced. Me fue muy bien en el examen de entrada al Colegio y me pusieron en el quinto año. Al fin de año recibí el título de profesora. Seguí para sexto año y al final recibí un certificado y me presenté al Ministerio de Educación para los exámenes de revisión. Pasé todo bien y me aceptaron en la Facultad de Odontología de la Universidad Nacional. Me gradué en 1941, la segunda mujer odontóloga de la historia de la Facultad ${ }^{180}$.

Gabriela Castro, que también fue estudiante del Pedagógico recordaba la buena nueva de que las jóvenes ya podían obtener el diploma de bachillerato, con lo cual se les abría un espectro más amplio de posibilidades de estudios profesionales. También ella se transfirió al Colegio de La Merced. Dejó constancia del traslado en la siguiente forma:

...En primer lugar, yo no tenía deseos de ser profesora; sinceramente... no era esa mi ilusión... mi ilusión era de ser profesional y realmente pensé ser ingeniera porque mi hermano mayor, que era ingeniero, me había ilusionado mucho con la ingeniería... Corno no había en la actualidad ningún colegio que diera el bachillerato en Colombia, me fui para el Instituto Pedagógico porque decían que era de lo mejor; entre otras cosas allí había estudiado mi hermana Maruja Castro que después se licenció también.

«En cuarto año nos dijo la Directora, la Dra. Radke 'Vamos a hacer una encuesta para saber quiénes están interesadas en obtener en seis años la Pedagogía, y el Bachillerato (en cinco años era solamente la Pedagogía). Lógicamente que todas dijimos seis años y las dos carreras. Pero el Ministerio (de Educación) no aprobó el plan de que el Instituto nos diera bachillerato sino que siguiera con orientación hacia la pedagogía.

Entonces las que teníamos deseos de bachillerato emigramos del Pedagógico. El curso nuestro que era de sesenta alumnas quedó reducido a la mitad. Algunas como Maruja Blanco entraron al Instituto Alice Block, otras como yo nos fuimos al Colegio de La Merced mientras que otras fueron donde las Salesianas (Colegio de María Auxiliadora) o a La Presentación (Centro). Esos fueron los cuatro colegios de Bogotá que se reorganizaron en un tiempo relativamente corto para ser aprobados por el Gobierno para el Bachillerato ${ }^{181}$.

Como lo señaló Gabriela Castro, aunque muchas estudiantes del Instituto Pedagógico se trasladaron al Colegio de La Merced, algunas se fueron al Instituto Alice Block, que era considerado como una institución privada modelo que preparaba a sus alumnas con éxito

\footnotetext{
${ }^{180}$ Entrevista: Dra. Blanca Garavito de Avila, Bogotá.

181 Entrevistas: Dra. Gabriela Castro de Barrera, Bogotá, Gabriela Castro Gómez nació en Bogotá el 11 de marzo de 1916 y murió en la misma ciudad el 13 de agosto de 1991 Fueron sus padres Don Florentino Castro Patiño y Doña Gabriela Gómez Malagón. Su esposo. Dr. Isidro Barrera fue también odontólogo. 
para recibir el diploma de bachillerato, aprobar los exámenes nacionales y solicitar su admisión a la universidad.

Maruja Blanco Cabrera, la primera mujer que se graduó, en 1940, en la Facultad de Odontología de la Universidad Nacional de Colombia, había terminado sus estudios de bachillerato en el Instituto Alice Block. En febrero de 1936 aprobó el examen nacional para obtener el diploma de bachillerato, siendo también la primera mujer que logró tal distinción en Colombia. Su destacado récord estudiantil fue muy elogiado ${ }^{182}$.

El Colegio Alemán, fundado por iniciativa de Don Antonio Kraus, muy conocido hombre de negocios de origen alemán, había iniciado sus actividades en $1922^{183}$. En 1934 tenía un total de 184 alumnos de uno u otro sexo y' de distintas nacionalidades (colombiana, alemana y otras). Sus programas de estudio, que cubrían enseñanza primaria y secundaria, preparaban a quienes recibían sus diplomas para ingresar en universidades y otras instituciones de estudios avanzados tanto en Colombia como en Alemania. En 1934 hubo tres estudiantes que terminaron sus estudios: Gerda Westendorff Restrepo, Jorge Silva y Alberto Michelsen. La colonia alemana de Bogotá, los directores y el personal docente del Colegio recibieron felicitaciones por el rendimiento de sus estudiantes. A principios de 1935, cuando Gerda Westendorff presentó con buenos resultados sus exámenes de admisión a la Facultad de Medicina de la Universidad Nacional de Colombia, fue objeto de grandes elogios por ser la primera mujer admitida en una facultad colombiana de medicina ${ }^{184}$.

El primer grupo de bachilleres del Gimnasio Femenino, otro colegio privado, se graduó en 1936. Tres estudiantes de esa clase, Helena Cano Nieto, Alicia Uribe Vergara y Teresa Muñoz Mariño, se matricularon en la Universidad Nacional de Colombia para estudiar bacteriología. Por iniciativa de un grupo de padres de familia de tradición política liberal, se fundó en 1928 el Gimnasio Femenino, para establecer una institución educativa para mujeres de las clases altas que las preparara para participar en la transformación social de Colombia. Quienes lo fundaron pensaban que la educación religiosa constituía un

\footnotetext{
${ }^{182}$ «Dos damas obtienen el bachillerato de manera muy brillante». El Tiempo, 1 de febrero de 1936. Las dos bachilleres fueron María Blanco Cabrera y Cecilia Caballero Ferreira. La primera mujer que pasó por examen oficial de bachillerato fué María Blanco Cabrera: también entrevista, Maruja Blanco Cabrera, Bogotá. Nota: al poco tiempo de su graduación, la Dra. Blanco se trasladó a Venezuela donde se estableció con su familia y ejerció su profesión por muchos años.

${ }^{183}$ El Colegio Alemán se inauguró en Bogotá en 1922 bajo la dirección del Dr. Fritz Gericke. Esta iniciativa había empezado en 1920-1921 con la organización de un colegio particular con siete niños, auspiciado por Don Anton Kraus. y dirigido por la Srita. Elizabeth Schrader. Los Sres. Reinhard Kling. Ernesto Schmidt-Munn y Carlos Wenz se asociaron a la iniciativa del Sr. Kraus, y el gobierno alemán contribuyó a esta iniciativa.

En 1931, el Colegio entonces conocido con el nombre de Deutscher schulverein, recibió personería jurídica, por medio de la Resolución 65 de 1931 (4 de diciembre), firmada por el Presidente Enrique Olaya Herrera y el Ministro dc Gobierno. Los primeros estudiantes de bachillerato terminaron en 1935. El Colegio se cerró en 1942 por orden del Ministerio de Educación a los cuatro colegios alemanes que existían en Colombia en ese entonces. En 1947, la Alexander von Humboldt Cultural Corporation se estableció en el local del plantel que en 1953 se transformó en el Colegio Andino. La autora le agradece a la Dra. Lucía Gómez de Rezk, graduada del Colegio Alemán en 1940 y a Doña Helga Raut, por proporcionarme datos sobre la fundación del Colegio.

${ }_{184}$ «En el Colegio Alemán», El Tiempo, $1^{0}$ de diciembre de 1934: Cecilia Hernández Mariño. «la mujer en la universidad». El Tiempo, 6 de marzo de 1935; Sonia González de Vengoechea. «Hace 50 años entró la primera mujer a la Universidad colombiana». El Tiempo, 6 de marzo de 1985; Obituario: "Gerda Westendorp de Núñez». El Tiempo, 26 de julio de 1996. Gerda Westendorp estudió medicina en la Universidad Nacional un año. Se casó en 1936 con Alfonso Núñez Arango. Posteriormente .completó su carrera universitaria en el campo de Filología e Idiomas. Fue profesora de alemán de la Universidad Nacional de Colombia.
} 
elemento importante en el programa de estudios, pero no querían que las jóvenes estudiantes fueran educadas en colegios regentados por miembros de órdenes religiosas que habían optado por alejarse del mundo. La primera Directora del colegio, Doña Celia Duque de Duque, quien había pertenecido a una orden religiosa, contaba con muchos años de experiencia como educadora en un colegio femenino en Bogotá y había trabajado con campesinas jóvenes en Medellín ${ }^{185}$.

Los colegios privados dirigidos por órdenes religiosas, como el Colegio de la Presentación (Centro), fundado en 1877 por las Hermanas de la Caridad Dominicas de la Presentación, se adaptaron en parte a las cambiantes circunstancias, gracias al interés y sugerencias de las alumnas y de los padres de familia. Cecilia Espinosa Cala, natural de Bogotá, y Magdalena Cancino, oriunda de Socorro en el Departamento de Santander, estudiaron juntas en ese colegio e ingresaron más tarde a la Universidad Nacional de Colombia. La iniciativa de Cecilia Espinosa para promover cambios en el colegio estuvo sin duda ligada a la influencia de su tía abuela, la Hermana San Vicente (Ana Joaquina Reyes Monroy Elizachea), que perteneció a la orden de la Presentación y había enseñado en el colegio.

Las mismas experiencias familiares de Cecilia Espinosa la habían puesto en contacto con la actualidad política y con temas relacionados con la mujer y con la historia de Colombia. Otra tía abuela suya. Georgina Fletcher, visitaba su casa con frecuencia. A diferencia de los colegios oficiales, que recibían la influencia directa de los estatutos gubernamentales y de la política de los órganos educativos locales, en los colegios privados también se sentía el peso de las opiniones de quienes los dirigían, de los padres y de los alumnos. Los relatos de Espinosa y Cancino revelan esa interacción entre los estudiantes, la familia y el colegio. La narración de Cecilia Espinosa sugiere que ella tuvo influencia directa, al proponer a la Directora del colegio que iniciara algunos cambios, según se indica en el siguiente aparte:

Dos años antes de terminar los estudios de secundaria, estando en La Presentación del Centro, pasé por el Ministerio de Educación para averiguar exactamente qué requisitos necesitaban los colegios para ofrecer el bachillerato. Regresé al Colegio y le hablé a la Hermana Superiora quien se interesó en ofrecer los cursos para las niñas que querían el bachillerato. Una de mis compañeras era Magdalena Cancino.

\footnotetext{
185 Los fundadores del Gimnasio Femenino fueron .Jorge Durana Camacho, Camilo Sáenz Obregón, Santuria García de Samper, Carlina Mariño de Muñoz, Inés Samper de Durana y otros. Esta tradición de que padres de orientación política liberal establecieran colegios para sus hijos no era nueva. Uno de los colegios para niñas y señoritas más conocidos fue el Colegio Pestalozziano dc Bogotá, fundado por Doña Eva Gooding de Cárdenas y su hermana Paulina Gooding en 1886. después de la Guerra Civil Colombiana de 1885, que resultó en la derrota del Partido Liberal. El Colegio tenía anexa para varones. Varias generaciones de mujeres de familias de tradición liberal se educaron en este colegio, entre ellas, Julia Rodríguez O., hermana del General Celso Rodríguez. Carlina Prada y Maria Isabel Pérez Sarmiento. Los jóvenes que se educaron en la Anexa fueron, entre otros, Bernardo Herrera Umaña, Alfonso López Pumarejo, futuro Presidente de Colombia y su hermano, Eduardo López Pumarejo, J. M. Pérez Sarmiento, «Doña Eva Gooding de Cárdenas», El Tiempo, 14 de Diciembre de 1936; Hernana Teresa de la Inmaculada, op. cit., pp.. 251-252.; Cincuenta años del Gimnasio femenino, Coordinación: Ana Iregui de González y Margarita Rueda de Ricaurte. Presidenta de la Asociación de Exalumnas: Trudv Kling de Martínez (Bogotá: Litografía Arco, 9 de septiembre de 1977); carta de Camilo Sáenz al Editor, E/Tiempo, 19 de febrero de 1928. La autora les agradece a las Dras. Inés Durana Samper, Alicia Dussan de Reichel y la Sra. Inés Ortega de Kinnane, cxalurnnas del Gimnasio Femenino, por su interés.
} 
Como parte de nuestro curso de bachillerato nos pidieron que compráramos libros de ciencias pero les recortaron la sección con los órganos reproductivos. Claro que yo siempre me leía los libros enteros antes de que les sacaran esas páginas ${ }^{186}$.

El relato de su experiencia como una de las primeras alumnas que terminaron el bachillerato en el colegio continúa así:

Cuando terminamos nuestros estudios la Directora no nos quería dar los 'cartones' (diplomas) sobre todo al saber que yo quería estudiar medicina... Para ella el ser «doctora» iba contra la naturaleza de la mujer. Hasta invitó al «Doctorcito» (Monseñor Emilio de Brigard) para que me viniera a hablar a ver si cambiaba de opinión. Aunque yo respetaba mucho al «Doctorcito» seguí con mí interés por la Medicina $^{187}$.

Cuando me pidieron que llevara mis notas a la Facultad de Medicina, la Directora al principio no me las quería dar. Entonces yo inventé el 'rumor' de que un Representante del Ministerio venía a visitar el Colegio. Mis notas se enviaron a la Facultad de Medicina al poco tiempo. Me especialicé cen ginecología y cuando terminé, la antigua Directora del Colegio me pidió que fuera su médica así como de muchas otras religiosas ${ }^{188}$.

\section{En busca de bachillerato fuera de la capital}

Las jóvenes que provenían de ciudades y pueblos donde el acceso a la educación secundaria pública no era fácil, demostraron la importancia de la actividad concertada de los padres para el logro de los objetivos educacionales que se buscaban. Mientras Cecilia Espinosa había nacido en Bogotá, Magdalena Cancino, su compañera de clase, era natural de Socorro, Santander. Cuando su familia la trajo a Bogotá la matricularon en el Colegio de La Concordia, una institución privada con sólida reputación desde hacía muchos años. El Colegio, fundado en 1868 por la destacada pedagoga Doña Avelina Moreno Uribe (1839-1923), oriunda también de Socorro, era dirigido por Clotilde Moreno

\footnotetext{
${ }^{186}$ Entrevistas, Dra. Cecilia Espinosa dc Delgadillo, Bogotá. La Dra. Espinosa terminó sus estudios de medicina en la Universidad Nacional en 1943. Después del internado y tesis, recibió su grado en 1949. Respecto a la fundación del Colegio de la Presentación (Centro), ver Beatriz Álvarez. OP. Hermanas de la Caridad Dominicas de la Presentación de la Santísima Virgen. Los diez primeros años de la implantación en Colombia» Archivos Dominicanos, Tomo IX, Salamanca, págs. 71-92: carta de Beatriz Álvarez 0.P. a la autora, Tours, La Breteche, Francia, $1^{0}$ de diciembre de 1994 (Nota: La Dra. Espinosa Cala nació en Bogotá el 5 de noviembre de 1920 y falleció en la misma ciudad el 18 de agosto de 1985).

${ }^{187}$ Monseñor Emilio de Brigard Ortiz, hijo de Luis de Brigard Sáiz y María Josefa Ortiz Álvarez, nació en Chía. Cundinamarca en 1888 y fué ordenado sacerdote Diocesano en1911. Recibió grados en teología y leyes canónicas en la Universidad Gregoriana de Roma. En Bogotá se dedicó al trabajo con niños abandonados y las condiciones de los trabajadores. Fue tambié capellán de varios colegios, entre ellos, el Colegio de la Presentación (Centro), el Gimnasio Femenino el Gimnasio Moderno. Fué profesor de la Universidad Javeriana y del Seminario Conciliar de Bogotá, así como de otras instituciones. En 1944 lo nombraron Obispo y fue Obispo Auxiliar de Bogotá hasta su Fallecimiento el 6 de marzo de 1986. Monseñor de Brigard, conocido como «El Doctorcito». Fue admirado por sus características de bondad y sencillez. (Ver José María Restrepo Sáenz y Raimundo Rivas. Genealogías de Santa Fe de Bogotá, Nueva edición, editores: Monseñor José Restrepo Posada, Mons. Bernardo Sanz de Santamaría.. Fenita Hollman de Villaveces. Maria Francisca Medina de Rocha, Juan Francisco Mantilla González, Miguel Wenceslao Quintero Guzmán, Eduardo Balén y Pizano, Fernando Restrepo Uribe. Jaime Herrera Pontón (Bogota: Editorial Presencia, 1991), pp. 345-363.

${ }^{188}$ Cecilia Espinosa de Delgadillo, Bogotá. Op. cit 
de Maldonado ${ }^{189}$. Las experiencias de Magdalena en este Colegio y más tarde en La Presentación (Centro) fueron recogidas en los párrafos siguientes:

De Socorro, Santander me trajeron a Bogotá y me pusieron en e Colegio de La Concordia que era de una señora santandereana, Clotilde Moreno de Maldonado. Era estupendo. Me tenían interna; yo era la más pequeñita. En el Colegio de La Concordia estuve cuatro años. El profesorado era magnífico, siempre avanzaba uno mucho. Yo tal vez era como muy buena en geografía, historia universal, y todo eso. Al fin de año en los grados de los mayores, me sacaban y me hacían examen delante de todo el público.., yo era pequeñita y me daban unos premios especiales... Era buena estudiante...

Después me cambiaron de colegio, pues no quería seguir interna. Me pusieron en el Colegio de La Presentación del Centro. Estudié en este colegio tres años. En aquel entonces el curso era de cinco o seis años... El ambiente no era tan intelectual, o que te digo, como La Concordia, pero estudiamos ciencias - física, química... y cuando se llegó el último año nosotras queríamos ser bachilleres. En el '36 (1936) nos organizamos para presentar los exámenes de bachillerato. Nos decían a Cecilia ya mí 'Que salgan las bachilleres...' Terminamos el año bien. No recibíamos título. Sólo en Colegios como en La Merced que recibían el título de profesora o especialista para trabajar en Comercio.

Cuando terminamos Cecilia y yo con ese entusiasmo que teníamos nos preparamos. En las vacaciones me pusieron en mi casa profesores de Matemáticas, de idiomas y de ciencias para poder presentarme al examen de revisión que era muy fuerte. Así fue como en 1937 Cecilia y yo, y jóvenes de otros colegios. junto con todos los varones, nos presentamos para los exámenes y pasamos. Me matriculé en la Facultad de Odontología aunque yo verdaderamente quería estudiar medicina ${ }^{190}$.

El testimonio de Magdalena Cancino mostró las circunstancias que enfrentaban las familias que vivían en regiones fuera de Bogotá, la capital, cuando buscaban que sus hijas estudiaran bachillerato. Tal proceso no era sencillo, ya que implicaba alejarlas del hogar o radicar la familia en lugares que ofrecieran mayores oportunidades. Claudina Múnera y las mujeres de Manizales que habían solicitado del Congreso el establecimiento por el gobierno de al menos un colegio modelo para mujeres en cada departamento, comprendían bien los problemas del bachillerato femenino. En realidad, durante la década que siguió a la aprobación del decreto 227 hubo muy pocos colegios oficiales de bachillerato femenino fuera de Bogotá y de Medellín.

Un factor adicional que contribuyó a obstaculizar la educación en zonas alejadas fue el temor de que desaparecieran los colegios exclusivos para hombres o mujeres. A partir de 1936 los intentos por incorporar a las jóvenes en colegios para varones, sobre todo en regiones remotas donde no había colegios de enseñanza secundaria femenina, pusieron en tela de juicio los conceptos vigentes acerca de las diferencias entre la naturaleza masculina y la femenina, así como de la educación apropiada para cada sexo. La experimentación con colegios mixtos fue criticada por las autoridades eclesiásticas y por

\footnotetext{
189 «Una gran pérdida. Doña Avelina Moreno Uribe». El tiempo, $1^{0}$ de Noviembre de 1923; "El entierro de la Señorita Avelina Moreno Uribe», El Tiempo, 2 de noviembre de 1923: "50 años Colegio de la Concordia. Reconocimiento ante el Congreso. Tiene Facultad para expedir grados de Institutoras». El Tiempo, 15 de octubre de 1917; Hermana Teresa de la Inmaculada. op. cit., pp. 76-79.

190 Entrevistas, Magdalena Cancino de Fresen, Bogotá. Nota: Magdalena Cancino nació en Socorro, Santander, el 13 de agosto de 1918 y falleció en Bogotá el 7 de abril de 1998.
} 
laicos. Los obispos locales condenaron la educación mixta en sus respectivas jurisdicciones, bajo amenaza de pecado mortal y excomunión.

Así, por ejemplo, a fines de 1936 los padres de los estudiantes del Colegio de Sevilla de la región del Valle, antes sólo para hombres, buscaron el apoyo del gobierno nacional. El Colegio de Sevilla, exclusivamente masculino, había admitido a mujeres como alumnas. A raíz de ello el Obispo de Cali amenazó a los padres de familia con someterlos a censura e interdicción si mantenían a sus hijos en el Colegio. El castigo de interdicción generalmente prohibía a quien lo sufriera, asistir a determinados servicios religiosos. Ante esa censura los padres de familia pidieron apoyo en telegramas dirigidos al Presidente de Colombia y al Congreso Nacional. Pedían, además, que se mantuviera la partida financiera anual para asegurar la continuidad del Colegio ${ }^{191}$.

De igual manera a principios de 1937 las alumnas de la Normal del Occidente, institución de capacitación pedagógica afiliada a la Universidad de Nariño, en Pasto, protestaron porque el Obispo de su diócesis había amenazado con censura y pecado mortal a los alumnos de uno u otro sexo que cursaran estudios en la misma institución, a sus maestros y a sus padres. Hubo apoyo público generalizado a los estudiantes y una representación del Concejo de Pasto viajó a Bogotá para formular sus quejas ante el Gobierno nacional ${ }^{192}$.

Darío Echandía, quien era entonces Ministro de Educación, expuso ante el Congreso Nacional el caso del Colegio de Sevilla. Afirmó que, según interpretación obtenida con la jerarquía eclesiástica de Bogotá, la educación mixta no se oponía a las normas de la iglesia, la moral cristiana, ni el derecho canónico. Era cuestión de costumbres locales. Echandía sugirió también que la práctica hacia recordar épocas pasadas, cuando el clero tenía una influencia más directa en las políticas y estrategias del sector de la educación en Colombia ${ }^{193}$.

Aún años más tarde las primeras mujeres que buscaron el bachillerato en regiones lejanas a fin de seguir carreras universitarias, enfrentaron la misma atmósfera de oposición a los colegios mixtos. Los continuos problemas experimentados por las mujeres jóvenes y sus familiares en sitios alejados pueden apreciarse en los relatos de Daisy Yela de Pasto, Graciela Hurtado de Palmira. Nubia Aristizábal de Buga y Leyka Nisimblat de Zarzal, Valle.

Daisy Yela, hija de padre colombiano y de madre francesa, había estudiado comercio en el Colegio del Sagrado Corazón, una institución de enseñanza secundaria dirigida por las hermanas Bethlemitas en Pasto, capital del departamento de Nariño. Había ingresado a ese colegio a la edad de quince años, a su llegada de Francia. El programa de comercio estaba considerado como el campo de estudios más avanzado que podían seguir las alumnas en esa región. La matricularon en ese Colegio por sugerencia de su tía paterna, la Madre Enriqueta Yela, que pertenecía a la congregación religiosa de las Bethlemitas. El Colegio ayudó a Daisy, nacida en Francia, a aprender con rapidez el español. No había, sin embargo, bachillerato para mujeres en Pasto y su padre, Don

\footnotetext{
${ }^{191}$ «El Colegio de San Simón es puesto en entredicho por decreto del Obispo». El Tiempo, $1^{0}$ de Diciembre de 1936.

192 El Tiempo, 15 de enero de 1937; «La Coeducación es otra vez condenada bajo pena de pecado por el Obispo», El Tiempo, 10 de febrero de 1937.

193 «Darío Echandía, Ministro de Instrucción Pública, Sesiones de la Cámara explicó la cuestión de las relaciones entre la Iglesia y el Estado», El Tiempo, 4 de diciembre de 1936.
} 
Antonio Yela, quería que sus hijas Daisy y Lylette se prepararan para ingresar a la facultad de medicina. Se aconsejó al padre de Daisy mudarse a la vecina región de Popayán. Cauca, donde las oportunidades para educar a sus hijas podrían ser mayores.

Toda la familia se mudó a Popayán, donde Don Antonio trabajó como profesor de francés y de literatura francesa. Se había recomendado a la Familia matricular a sus hijas en el Colegio de María Auxiliadora, pero éste no había establecido todavía el bachillerato. Se le había aconsejado también a Don Antonio intentar que se las recibiera en el colegio masculino afiliado a la Universidad del Cauca. Don Antonio tuvo éxito en el intento de matricularlas en ese colegio y en 1942 las dos jóvenes se convirtieron en las primeras mujeres graduadas en la sección de bachillerato de la Universidad del Cauca. El Maestro Baldomero Sanín Cano, reconocido paladín de la causa femenina, era rector de la universidad.

Debido a que el padre de Daisy deseaba que sus hijas solicitaran admisión en la facultad de medicina y en Bogotá, la capital del país, había oportunidades para ello, la familia se movió de nuevo. De hecho, Daisy y su hermana Lylette ingresaron a la Facultad de Farmacia de la Universidad Nacional de Colombia. La decisión de seguir la carrera de farmacia en lugar de medicina fue en parte accidental. Cuando al llegar a Bogotá la familia se alojó inicialmente en un hotel, el director de la Facultad de Farmacia, que había estudiado en Francia, se enteró del interés de las dos hermanas por estudiar y las convenció de que estudiaran farmacia. Ingresaron en la Facultad de Farmacia de la Universidad Nacional.

El traslado a Bogotá implicó nuevos sacrificios financieros. Para afrontar los gastos la madre de Daisy, Thérése Janet, complementó los ingresos familiares trabajando como modista principal en el taller del Salón Margarita, que en aquella época era el mejor centro de alta costura de Bogotá. Daisy y Lylette terminaron sus estudios de farmacia en 1946. Las cinco mujeres que formaban parte del grupo de treinta graduandos, venían de fuera de Bogotá ${ }^{194}$.

No obstante, trasladar a la familia con el ánimo de buscar oportunidades educativas para los hijos no era siempre factible o posible. Para algunas jóvenes, como Graciela Hurtado, oriunda de Palmira (departamento del Valle), el camino hacia la culminación del deseado bachillerato, en un colegio que antes era únicamente para hombres, provocó la sanción de las autoridades eclesiásticas. A falta de instituciones de educación femenina la mayoría de los dirigentes tradicionales de la comunidad y sus familias no consideraban la enseñanza mixta como una opción válida. Graciela había querido estudiar cursos que la prepararan para el bachillerato desde cuando estaba en primaria. Como en Palmira, sin embargo, no se ofrecía educación secundaria para la mujer, y ante el hecho de que su familia no disponía de recursos para enviarla a Bogotá, se quedó en el colegio elemental dos años adicionales, para absorber todo lo que en ese tiempo podía aprender una niña. Se trataba básicamente de temas comerciales.

Más tarde algunos padres de familia decidieron matricular a sus hijas en el Colegio Cárdenas, de bachillerato para varones en Palmira. Graciela estudió en ese ambiente de coeducación hasta el último año de bachillerato cuando su padre, Don Ricardo Hurtado Torres se vio forzado a retirarla del Colegio debido a la amenaza de excomunión general del Arzobispo de Popayán contra las familias que habían matriculado a sus hijas en

\footnotetext{
${ }^{194}$ Entrevistas, Daisy Yela, Cali. 
instituciones de educación mixta. A través de sus sermones condenatorios desde el púlpito, el párroco de Palmira dio aún mayor fuerza a las órdenes del Arzobispo.

El padre logró contar con el dinero suficiente para enviar a Graciela a Bogotá, donde estudió en el Liceo Nacional Femenino Antonia Santos, un colegio secundario de carácter oficial fundado en 1940 para ofrecer estudios de bachillerato femenino. Graciela recordaba, sin embargo. que al principio ningún colegio secundario para mujeres de Bogotá quería admitirla, por haber estado en un colegio de varones, lo cual comentaba diciendo: "es que pensaban que viniendo de un colegio de varones quien sabe que clase de moral llevaríamos... La coeducación no era admitida». El Liceo Nacional Femenino Antonia Santos, que inicialmente había vacilado en admitirla, ofreció por fin considerar su solicitud siempre que la familia consiguiera cartas de recomendación adecuadas. Graciela obtuvo tal carta de Don Elías Quijano, quien era Director de Enseñanza Secundaria en el Ministerio de Educación. Conocido propulsor de la educación en la zona del Valle, Don Elías había conocido a Graciela desde cuando fue Director del Colegio Cárdenas ${ }^{195}$. Graciela se acordaba de las palabras de Don Elías: "Recíbanla a ella y a todas las niñas que vengan de allá, que serán 'timbre y orgullo' para ese Colegio.» La recibieron y terminó su bachillerato en 1943. Graciela entró a la Facultad de Medicina de la Universidad Nacional en 1944, terminó sus estudios en 1949 y después de hacer el internado rural y presentar su tesis, se graduó el 3 de octubre de $1952^{196}$.

En determinadas localidades los padres de familia y los administradores de los colegios se opusieron algunas veces con éxito a las sanciones eclesiásticas impuestas a los modelos de coeducación. La presión negativa experimentada por aquellos padres de familia que quisieron abrir nuevos caminos para la mujer en la sociedad de aquella época. es aparente en la narración de Nubia Aristizábal, nacida en Buga, Valle. En 1940 Nubia, junto con otras jóvenes se matriculó en un nuevo colegio, el Liceo Femenino, fundado también por Don Elías Quijano. Antes que existiera este colegio, a las niñas que tenían aspiraciones y deseaban estudiar bachillerato se las enviaba al «norte», a Manizales, capital del departamento de Caldas. Esa alternativa era, sin embargo, costosa y muchas familias no podían sufragarla.

El nuevo instituto era una sección femenina del Colegio Académico de Buga, el colegio de varones de la ciudad. El primer año el nuevo colegio fue dirigido por el rector del Colegio Académico y observó las normas educativas del Ministerio de Educación para las instituciones de enseñanza secundaria. Las alumnas estaban en el edificio vecino al Colegio Académico, lo cual facilitaba la posibilidad de que los profesores del Colegio también les dieran clases a ellas. Pagaban mensualidades de cinco pesos. Al principio del segundo año, sin embargo, algunas alumnas dejaron el colegio y éste no pudo darse el lujo de tener un profesorado propio, por lo cual Don Elías sugirió que las estudiantes

\footnotetext{
${ }^{195}$ Don Elías Quijano, educador de renombre en las regiones del Valle y del Cauca. Fundó la Normal de Cali y fue también inspector escolar. Sus innovaciones en el campo de la educación fueron adoptadas por el Ministerio de Educación.

Fue Director de varios colegios, entre ellos, el recién reformado Gimnasio del Pacífico de Tulúa, el Colegio de Santa Librada de Cali y el Colegio Cárdenas de Palmira. En 1940, siendo Director del histórico Colegio Académico de Buga, estableció el Liceo Femenino, anexo al Colegio Académico. Desempeñó cargos administrativos de importancia, entre ellos, el cargo de Vice Rector de la Universidad del Cauca, profesor y miembro del Consejo Directivo de dicha Universidad; Director de Educación Pública del Valle, y Secretario General de Educación del Ministerio de Educación, siendo Ministro de Educación el Dr. Mario Carvajal. Falleció en 1947.

La autora le agradece a la Dra. Nubia Aristizábal y a Doña Elisa Quijano de Bravo, Cali, hija de Don Elías, por datos biográficos. Ver también. El Tiempo, 7 de abril de 1933.

${ }^{196}$ Entrevistas, Dra. Graciela Hurtado de Mazariegos, Cali. 
asistieran a clase junto con los varones. Los recreos y actividades similares se mantuvieron en locales separados para hombres y mujeres.

Después que Nubia asistió a clases junto con los varones en ese nuevo esquema coeducacíonal, le comunicó a su madre Doña Ana Rodríguez de Payán, que había oído el rumor de que a los padres que habían permitido que sus hijas participaran en ese nuevo arreglo de enseñanza mixta se les iba a amenazar con excomunión. Su madre le respondió que de todos modos ella ya estaba excomulgada por leer el diario liberal El Tiempo, Doña Ana aseguró a su hija que no podían excomulgarla dos veces.

En el acta del Colegio Académico del 10 de octubre de 1940 consta que en esa fecha se discutió el telegrama que el Obispo de la Diócesis había enviado al párroco de Buga advirtiéndole que no ofreciera colaboración ni apoyo al Colegio, porque estaba implantando la educación mixta. El telegrama había sido leído desde el púlpito en una misa dominical. En su reunión de octubre la administración del colegio y los miembros de la Junta Directiva, resolvieron responder al párroco de la localidad, Dr. Lisandro Roda, explicando las providencias adoptadas, que han sido ya explicadas ${ }^{197}$. Finalmente el problema se resolvió en forma satisfactoria y las primeras graduadas del Liceo Femenino terminaron sus estudios en 1947. Nubia ingresó luego en Bogotá a la Facultad de Medicina de la Universidad Nacional de Colombia, donde terminó sus estudios en $1954^{198}$.

En los pueblos y las pequeñas ciudades las mujeres jóvenes y sus familias superaron los obstáculos planteados por la escasez de recursos educativos. El bachillerato empezaba a surgir como alternativa a la tradicional educación femenina en las escuelas normales. El conjunto de circunstancias que las estudiantes de áreas rurales y pequeñas ciudades enfrentaban, impulsó a Leyka Nisimblat, nacida en Zarzal, Valle, a salir de la renombrada Normal de Señoritas de Ibagué e ingresar al Gimnasio del Pacífico, en Tuluá, el colegio de bachillerato para varones cerca de su casa.

Leyka había obtenido una beca para estudiar en la Escuela Normal de Ibagué. Poco antes que entrara en su cuarto año de estudios, informaron a su madre que la beca no sería renovada. Leyka se enteró de que el problema tenía relación con su edad y con las responsabilidades que debían asumir las estudiantes de cuarto año en las prácticas de campo con alumnas de grados inferiores. Leyka tenía entonces 14 años. Muchas alumnas provenientes de medios rurales que estaban en grados inferiores tenían 16 ó 17 años, porque habían empezado tarde sus estudios. Las autoridades escolares no querían que las alumnas jóvenes de los grados superiores supervisaran la práctica de estudiantes mayores de los grados inferiores. Ante tales circunstancias Leyka dejó la Normal de Ibagué. En cierta forma le complació el cambio, porque empezaba a preguntarse si realmente tenía vocación de maestra. Como alternativa, ella y otras dos jóvenes ingresaron al Gimnasio del Pacífico, en Tuluá, que antes había sido sólo para varones. Después de terminar sus estudios de bachillerato su solicitud de admisión fue aceptada por la Facultad de Derecho, Universidad del Cauca.

Mirando retrospectivamente todas esas experiencias, Leyka destacó la influencia de sus padres, Rosaura Álvarez y Oscar Nisimblat. Estimularon a sus ocho hijos para que estudiaran, e inculcaron en todos, hijos e hijas, iguales deseos de superación ${ }^{199}$.

\footnotetext{
${ }^{197}$ Acta N ${ }^{0}$ 2, 10 de octubre de 1940, en Libro de Actas, Colegio Académico de Buga, 1940. Rector: Elías B. Quijano. Secretario: Daniel Caicedo. (Actas, cortesía de la Dra. Nubia Aristizábal).

198 Entrevistas, Dra. Nubia Aristizábal, Cali.

${ }^{199}$ Entrevistas, Dra. Leyka Nisimblat, Cali. 
Las experiencias de estas jóvenes nacidas fuera de Bogotá y de sus familias ilustran los retos que enfrentaron en un período de transformación de la sociedad colombiana. La ciudad de Medellín tiene interés en este campo, porque tanto hombres como mujeres fueron participantes activos en campañas de promoción de la educación y en otros cambios sociales.

En 1935, o sea el año en que se inauguró la sección de bachillerato del Colegio de La Merced, en Bogotá, las mujeres de Medellín se movilizaron activamente para conseguir apoyo para que se estableciera un colegio público de bachillerato femenino en Medellín. En efecto, a principios de enero de 1935 había grandes expectativas porque Medellín esperaba la aprobación de una ordenanza que crearía el primer colegio que ofreciera bachillerato para la mujer. Las mujeres del Centro Femenino de Estudios trabajaron con diligencia en favor de esa legislación pendiente en la Asamblea Departamental de Antioquia. Sus esfuerzos, no obstante, habrían de sufrir el impacto de los retos inesperados de la política cambiante tanto en la región como en el país. 